\title{
VII. Of the reaction of the essential oils with sulphurous acid, as evolved in union with æther in the process of ætherification, or otherwise
}

\section{R. Hare M.D.}

To cite this article: R. Hare M.D. (1838) VII. Of the reaction of the essential oils with sulphurous acid, as evolved in union with æther in the process of ætherification, or otherwise , Philosophical Magazine Series 3, 13:79, 28-32, DOI: 10.1080/14786443808649525

To link to this article: http://dx.doi.org/10.1080/14786443808649525

曲 Published online: 01 Jun 2009.

Submit your article to this journal

ЏII Article views: 2

Q View related articles $\longleftarrow$ 
benzoate, \&c. from falling, but not enough to cause the formation of the double salt. A crystalline precipitate, indeed, fell, but it was only oxalate, with a few flakes of the double salt. After drying at 212 it weighed 23.16 grs. and lost when heated to redness 26.85 per cent. Pure dry oxalate contains 24.68 per cent. of acid; and $23.16 \mathrm{grs}$. of oxalate are equivalent to $5 \cdot 71$ of anhydrous acid, very nearly the quantity employed. Some time must be allowed for the perfect deposition of the whole of the oxalate or of its double salt.

From these experiments it appears that by simply acidifying strongly with nitric acid, the oxalic may be separated almost completely from solutions containing any of the other organic acids above enumerated, and its quantity determined with considerable accuracy.

The utility of this process in separating the oxalic acid, formed so largely in the preparation of the indigotic and carbazotic acids and other highly oxidized compounds, need not be pointed out, nor the means it affords us of estimating quantitatively the nature of the changes produced on organized bodies by the action of oxidizing agents.

Durham, May 29, 1838.

VII. Of the Reaction of the Essential Oils with Sulphurous Acid, as evolved in union with AEther in the Process of Atherification, or otherwise. By R. Hane, M.D., Professor of Chemistry in the University of Pennsylvania*.

HAVING mixed and subjected to distillation two ounces of oil of turpentine, four ounces of alcohol and eight ounces of sulphuric acid, a yellow liquid came over, having all the appearance of that which is obtained in the process for making oil of wine, described in a preceding article. On removing, by means of ammonia, the sulphurous acid existing in the liquid, and driving off the æther by heat, a liquid remained, which differed from oil of turpentine in taste and smell, although a resemblance might still be traced. This liquid was without any sensible action on potassium, which continued bright in it for many weeks. It proved, on examination, to contain a small quantity of sulphuric acid. I ascertained, afterwards, that in order to produce these results, it was sufficient to pour oil of turpentine on the mass which remains after the termination of the ordinary operation for obtaining æther, and apply heat. Subsequently it was observed that when the sulphurous æther was removed by heat

* From the Transactions of the American Philosophical Society, N.S. vol, v. 
or evaporation, without the use of the ammonia, the proportion of sulphuric acid in the remaining oil was much greater.

By subjecting to the same process several essential oils, I succeeded in obtaining as many liquids to which the above remarks were equally applicable. With some of the oils, however, similar results were, by this method, either totally or partially unattainable, in consequence of their reaction with the sulphuric acid being so energetic as to cause their decomposition before any distillation could take place. No product can be obtained by distillation with sulphuric acid and alcohol from the oil of cinnamon obtained from cassia. From the oils of sassafras and cloves, but little can be procured.

However, in one instance, by previously mixing the oil of sassafras with the alcohol, in the manner described in the account given of the first experiment with the oil of turpentine, I succeeded in obtaining in addition to a small quantity of the heavy liquid containing sulphuric acid, a minute quantity of a lighter one, devoid of that acid, which burned without smoke, was insoluble in water, and very fluid. I am disposed to consider the liquid thus procured as a hydrate of sassafras oil, or sassafreine, as I would call it, being analogous to hydric æther.

The oil of sassafras, whether isolated or in combination, possesses a remarkable property, which, I believe, has not attracted sufficient observation: I mean that of producing an intense crimson colour, when added, even in a very minute quantity, to concentrated sulphuric acid.

One drop of oil of sassafras imparted a striking colour to forty-eight ounce measures of sulphuric acid, and appeared perceptible when it formed less than a five millionth part. This property was completely retained by the lighter liquid above described as procured from oil of sassafras.

I subsequently observed, that when sulphurous acid, whether in the form of sulphurous æther, in that of a gas, or when in union with water, was brought into contact with any of the essential oils (including kreosote), which were subjected to the experiment, they acquired a yellow colour, and a strong smell of this acid.

In the case of the yellow compound thus obtained from any of the essential oils which I have tried, if the sulphurous acid be removed by heat, the oil, by analysis, will be found to yield sulphuric acid. That some acid of sulphur remains in union must be evident, since washing with ammonia will not entirely remove the power of yielding sulphuric acid ; and the total absence of the sulphurous smell demonstrates that 
the sulphurous acid either enters into an intimate combination with the oil, or acquires oxygen sufficient to convert it into sulphuric or hyposulphuric acid.

Those essential oils which contain oxygen, are most affected by the action of sulphurous acid.

Both the oils of cloves and cinnamon, after admixture with sulphurous æther and subsequent distillation, gave, on analysis, precipitates of sulphate of barytes. In the case of cloves, the precipitate amounted to one-seventh of the whole weight.

By distilling camphor with alcohol and sulphuric acid, I obtained a yellow liquid, which, by washing with ammonia and evaporation, in order to get rid of the sulphurous æther, yielded an oil. The oil, by standing, separated into two portions, one solid, the other liquid. The solid portion resembled camphor somewhat in smell, but differed from it by melting at a much lower temperature, becoming completely fluid at $175^{\circ}$.

I found that the essential oils of cinnamon and cloves possessed an antiseptic power, quite equal to that of kreosote, and that their aqueous solutions, when sulphated, were even superior to similar solutions of that agent.

One part of milk mingled with four parts of a saturated aqueous solution of the sulphated oil of cloves, remained after five days sweet and liquid, while another portion of the same milk became curdled and sour within twenty-four hours. Having on the 2nd day of July added two drops of oil of cinnamon to an ounce measure of fresh milk, it remained liquid on the 11th; and, though it finally coagulated, it continued free from bad taste or smell till September, although other portions of the same milk had become putrid. A half ounce of milk, to which a drop of sulphurous oil of turpentine had been added, remained free from coagulation at the end of two days, while another portion, containing five drops of pure oil of turpentine, became curdled and sour on the next day.

A number of pieces of meat were exposed in small wine glasses, with water impregnated with solutions of the various essential oils. Their antiseptic power seemed to be in the ratio of their acridity. The milder oils seemed to have comparatively little antiseptic power, unless associated with the sulphurous acid, which has long been known as an antiseptic.

In cutaneous diseases, and, perhaps, in the case of some ulcers, the employment of the sulphurous sulphated oils may be advantageous.

A respectable physician was of opinion that the sulphurous 
sulphate of turpentine had a beneficial influence in the case of an obstinate tetter.

Possibly the presence of sulphurous acid may increase the power of oil of turpentine as an anthelmintic.

Pieces of corned meat hung up, after being bathed with an alcoholic solution of the sulphurous sulphated oil of turpentine, or with solutions of the sulphated oils of cloves or cinnamon, remained free from putridity at the end of several months. That imbued with cinnamon had a slight odour and taste of the oil.

I am led, therefore, to the impression that the antiseptic power is not peculiar to kreosote, but belongs to other acrid oils and principles, and especially to the oils of cinnamon and cloves.

The union of sulphuric acid with these oils appears to render them more soluble in water: whether any important change is effected in their medical qualities by the presence of the acid may be a question worthy of attention.

I have stated my reasons for considering the ammoniacal liquid, resulting from the ablution of the æthereal sulphurous sulphate of æetherine with ammonia, as partially composed of hyposulphuric acid. By adding to this ammoniacal liquid a quantity of sulphuric acid, sufficient to produce a strong odour of sulphurous acid, and then a portion of any of the essential oils; a combination ensued, as already described, between the oils and the sulphurous acid liberated by the sulphuric acid, so as to render them yellow and suffocating. The habitudes of cinnamon oil from cassia under these circumstances were peculiar. A quantity of it was dissolved, communicating to the liquid a reddish hue. The solution being evaporated, a gummy translucent reddish mass was obtained, which, by solution in alcohol, precipitated a quantity of salt, and being boiled nearly to dryness, redissolved in water and again evaporated, was resolved into a mass having the friability, consistency, and translucency of common rosin; but with a higher and more lively reddish colour. Its odour recalls, but faintly, that of cinnamon; its taste is bitter and disagreeable, yet recalling that of the oil from which it is derived. Its aqueous solution does not redden litmus; nor, when acidulated with nitric acid, does it yield a precipitate with nitrate of barytes.

Of this substance ten grains were exposed to the process above mentioned, for the detection of sulphuric acid, and were found to yield a precipitate of 6.5 grains of sulphate of barytes.

It may be worth while to mention, that in boiling the sul- 
phated oils with nitric acid, compounds are formed finally, which resist the further action of the acid, and are only to be decomposed by the assistance of a nitrate and deflagration. I conjecture that these compounds will be found to merit classification as æthers formed by an oxacid of nitrogen.

One of my pupils, in examining one of the compounds thus generated, was, as he conceived, seriously affected by it, suffering next day as from an over dose of opium. He also conceived that a cat, to which a small quantity was given, was affected in like manner.

I had prepared an apparatus with the view of analysing accurately the various compounds above described or alluded to, by burning them in oxygen gas; when, by an enduring illness of my assistant, and subsequently my own indisposition, I was prevented from executing my intentions.

VIII. On a Scale of Geometrical Equivalents for Engineering and other Purposes. By Mr. Charles Holtzanpfiel, Associate of the Institution of Civil Engineers.

\section{To the Editors of the Philosophical Magazine and Joumal.} Gentlemen,

THE scale of geometrical equivalents is a particular combination of several of the scales of equal parts, which $I$ have recently contrived and explained * : by means of this instrument, with the aid of a little arithmetic, a great variety of tedious calculations in constructive science generally, but more especially in engineering, may be performed with considerable correctness, by the simple inspection of scales, proportionals to the quantities under observation.

As regards drawing, the scales are shown to be only an extension and generalization of the common application of reduced scales of $1,2,3, \& c$. inches to the foot; and in their application to numbers or quantity, they are laid side by side with their zeros in contact, after the manner of thermometer scales, two of which are frequently engraved on the same instrument for comparison, so that we may read the height of the mercury either by the centigrade scale, freezing being called zero, and boiling 100 ; or by the Fahrenheit scale in common use in this country, the same space being divided into 180 degrees, freezing being then marked 32 . We may thus transpose the French reading of the instrument into the English, or the reverse.

I have extended this latter application of scales to many

* A new System of Scales of Equal Parts, by C. Holtzapffel. 